\title{
Performance of femtosecond laser-assisted cataract surgery in Chinese patients with cataract: a prospective, multicenter, registry study
}

\author{
Xiaobo Zhang ${ }^{1}$, Yinhui Yu' ${ }^{1}$ Guangbin Zhang ${ }^{2}$, Yanwen Zhou ${ }^{3}$, Guangyu Zhao ${ }^{4}$, Maosheng Chen ${ }^{5}$, Yong Wang ${ }^{6}$,
} Siquan Zhu' ${ }^{7}$, Hong Zhang ${ }^{8}$ and Ke Yao ${ }^{1 *}$

\begin{abstract}
Background: This study aimed to investigate the completion rate, visual performance, and adverse outcomes of femtosecond laser-assisted cataract surgery (FLACS) in Chinese patients.

Methods: This is a prospective, single-arm, multicenter registry study of 19 cataract surgery clinics in China. Chinese patients with cataract who underwent FLACS using the Alcon LenSx ${ }^{\oplus}$ laser system in single eye $(n=1140)$ or both eyes $(n=201)$ were enrolled and data were collected between March 2015 and August 2016. Clinical characteristics were recorded before surgery, and on postoperative days 1, 7, and 30. For surgery on both eyes, the second eye was included in the analysis only if it was operated within 30 days after the first eye surgery. The primary outcome was the completion rate of circular anterior capsulotomy. Secondary outcomes for lens fragmentation, corneal incision, and intraocular lens (IOL) implantation included best corrected distance visual acuity (BCDVA) and completion rates. Adverse events (AEs) were recorded.
\end{abstract}

Results: The completion rates of circular anterior capsulotomy, lens fragmentation, corneal incision, and IOL implantation were 98.6\% (95\% Cl: 97.8-99.1\%), 99.5\% (95\% Cl: 99.1-99.8\%), 97.6\% (95\% Cl: 96.7-98.3\%), and 100\% (95\% Cl: 99.8-100\%), respectively. BCDVA preoperatively and at postoperative day 30 were $1.134 \pm 0.831$ logMAR and $0.158 \pm 0.291$ logMAR, respectively. The proportion of eyes with BCDVA of 20/20 or better was $1.6 \%$ at baseline and $41.3 \%$ at postoperative day 30 . AE incidence was $0.32 \%$, with posterior capsule rupture present in $0.19 \%$ of eyes.

Conclusion: FLACS using the LenSx $x^{\oplus}$ laser system can achieve satisfactory results in a real-world setting.

Keywords: Femtosecond laser-assisted cataract surgery, Intraoperative complication, Chinese patients

\section{Background}

Cataract is a major global health problem and the most common underlying cause of reversible blindness worldwide $[1,2]$. In 2010, cataract was responsible for blindness in nearly 11 million people and visual impairment in a further 35 million people [3]. Socioeconomic factors are known to influence cataract prevalence and management [4], and developing countries have a higher prevalence of blindness due to cataract [3]. In China, cataract

\footnotetext{
* Correspondence: xlren@zju.edu.cn

'Eye Center, Second Affiliated Hospital, School of Medicine, Zhejiang University, Hangzhou, China

Full list of author information is available at the end of the article
}

is the major cause of blindness, and the prevalence of age-related cataract has been estimated to be $38.1 \%$ [5].

The management of cataract involves surgery and cataract operations are amongst the most common surgical procedures performed worldwide, although cataract surgery rates (CSR) vary widely between developed and developing countries [6]. The conventional technique involves the use of a small incision plus phacoemulsification to remove the lens material followed by the insertion of an intraocular lens (IOL). In this method, the ophthalmic surgeon opens the anterior lens capsule with surgical instruments, a procedure known as continuous curvilinear capsulorhexis (CCC). In recent years, there

(c) The Author(s). 2019 Open Access This article is distributed under the terms of the Creative Commons Attribution 4.0 International License (http://creativecommons.org/licenses/by/4.0/), which permits unrestricted use, distribution, and 
has been an increase in the use of femtosecond laser-assisted cataract surgery (FLACS), which has been reported to have several advantages over conventional methods with regard to opening of the anterior capsule $[7,8]$. Several studies have found that FLACS creates circular, smooth and rupture-resistant capsulotomies [9] that are at least as strong if not stronger than manual capsulorhexis [10]. FLACS can achieve capsulotomies that are more circular and more accurate in size than manual capsulorhexis $[11,12]$. Furthermore, FLACS has been reported to result in better IOL centration than manual capsulotomy [13]. Another recognized benefit of FLACS compared to the conventional technique is the reduction in phacoemulsification time and cumulative dissipation energy $[14,15]$. In addition, there are some evidences that recovery of visual acuity is faster with FLACS than manual capsulorhexis $[12,16]$. Importantly, FLACS is considered to be associated with a similar or perhaps lower incidence of intra-operative and post-operative complications than conventional phacoemulsification [17, 18]. Moreover, most investigations indicate that changes in corneal endothelial cell density, corneal thickness and/or central retinal thickness are similar or smaller for FLACS than for manual capsulorhexis [19-21].

Nevertheless, there are limited 'real-world' data regarding the performance of FLACS in the management of cataract. Real-world data have comprehensive guiding significance in objective evaluation of the novel technique. Therefore, the aim of the present study was to investigate the performance of the Alcon LenSx ${ }^{\circ}$ laser system in real-world medical practice.

\section{Methods}

\section{Study design and patients}

This was a prospective, single-arm, multicenter, registry study. Chinese patients with cataract who underwent FLACS in 19 cataract surgery clinics in China (Table 1) using the LenSx $x^{\circ}$ laser system in at least one eye between March 2015 and August 2016 were enrolled. The inclusion criteria were: 1) patients with age-related cataract or complicated cataract; 2 ) $\geq 18$ years of age; 3 ) planned to receive LenSx $\mathrm{x}^{\circ}$ laser-assisted cataract surgery and phacoemulsification in at least one eye; and 4) written informed consent was provided by the patient prior to enrolment in the registry. The exclusion criteria were: 1 ) had contraindication to FLACS, as listed in the LenSx ${ }^{\circ}$ laser system operator's manual (e.g. pupils dilation of < $5.0 \mathrm{~mm}$, small palpebral fissure, nystagmus, severe conjunctivochalasis, small hyperopic eyes with steep cornea (hard for suction), dense cornea scars and edema, uncooperative patient, or a functioning bleb, tube, or valve); 2) women who were pregnant, nursing or planning a pregnancy; 3) participated in other clinical trials before
Table 1 Number of subjects treated by investigator site

\begin{tabular}{|c|c|c|}
\hline Number & Site & $\begin{array}{l}\text { Enrolled subjects } \\
(N=1341), n(\%)\end{array}$ \\
\hline$\overline{01}$ & $\begin{array}{l}\text { The 2nd Affiliated Hospital } \\
\text { of ZheJiang University }\end{array}$ & $190(14.2)$ \\
\hline 02 & $\begin{array}{l}\text { The 4th Affiliated Hospital } \\
\text { of China Medical University }\end{array}$ & $67(5.0)$ \\
\hline 03 & $\begin{array}{l}\text { Tianjin Medical University } \\
\text { Eye Hospital }\end{array}$ & $90(6.7)$ \\
\hline 04 & Shanxi Eye Hospital & $38(2.8)$ \\
\hline 05 & Jinan Mingshui Eye Hospital & $63(4.7)$ \\
\hline 07 & ChiaMan Eye Hospital & $114(8.5)$ \\
\hline 08 & Chongqing Aier Eye Hospital & $102(7.6)$ \\
\hline 09 & Fuzhou South East Eye Hospital & $92(6.9)$ \\
\hline 10 & Wuhan Aier Eye Hospital & $108(8.1)$ \\
\hline 11 & Yinzhou Eye Hospital & $22(1.6)$ \\
\hline 12 & The 180th Hospital of PLA & $47(3.5)$ \\
\hline 13 & Weifang Eye Hospital & $71(5.3)$ \\
\hline 14 & $\begin{array}{l}\text { Shandong Shi E Ming } \\
\text { Eye Hospital }\end{array}$ & $37(2.8)$ \\
\hline 15 & $\begin{array}{l}\text { Beijing Tongren Hospital, } \\
\text { Capital Medical University }\end{array}$ & $91(6.8)$ \\
\hline 16 & Shenyang Aier Eye Hospital & $131(9.8)$ \\
\hline 17 & Mianyang Center Hospital & $46(3.4)$ \\
\hline 18 & $\begin{array}{l}\text { Nanjing South East } \\
\text { Eye Hospital }\end{array}$ & $12(0.9)$ \\
\hline 19 & $\begin{array}{l}\text { The Eye Hospital } \\
\text { of WMU - Hangzhou }\end{array}$ & $16(1.2)$ \\
\hline 21 & $\begin{array}{l}\text { The 2nd Affiliated Hospital } \\
\text { of Dalian Medical university }\end{array}$ & $4(0.3)$ \\
\hline
\end{tabular}

enrollment, or did not cooperate in the examinations, or did not adhere to the follow-up; or 4) had any other conditions that warranted exclusion based on the physician's judgment. This study was approved by the ethics committees of all the participating centers (Additional file 1) and adhered to the principles of the Declaration of Helsinki. Patients were withdrawn from the study if serious intraoperative complication occurred, including loss of vitreous, hyphema, intraocular hypertension, capsule rupture, endophthalmitis, conjunctivitis, or infectious keratitis. Their data would be captured in adverse event $(\mathrm{AE})$ reports.

\section{Baseline data collection}

The following baseline characteristics were recorded at a screening visit (1-30 days before surgery) or on the day of surgery: age, sex, ethnicity, uncorrected distance visual acuity (UCDVA, logarithm of the minimal angle of resolution $[\log M A R])$, best corrected distance visual acuity (BCDVA, logMAR and Snellen Chart), maximum keratometry reading (Kmax, D) and minimum keratometry reading (Kmin, D), axial length $(\mathrm{mm})$, nuclear 
density with the Emery-Little classification (soft, semisoft, semi-hard, hard or very hard) [22], endothelial cell count (per $\mathrm{mm}^{2}$ ), and pupil status. Visual acuity was assessed with a standard logarithm visual acuity chart and Snellen Chart. Keratometry was assessed with an IOL-Master 500 (Carl Zeiss Meditec AG, Iena, Germany), a LenSTAR LS 900 (Haag-Streit AG, Koeniz, Switzerland), or a Scheimpflug imaging system (Pentacam, OCULUS Optikgerate GmbH, Wetzlar, Germany). Axial length was measured with an IOL-Master 500 (Carl Zeiss Meditec AG, Iena, Germany) or a LenSTAR LS 900 (Haag-Streit, Koeniz, Switzerland). When the lens was too opaque for measurement, A-scan (A-mode US, Cinescan, Quantel Medical, Cournon-d'Auvergne, France) was used.

\section{Surgical technique}

All surgeons from 19 cataract surgery clinics received unified surgical training at the Second Affiliated Hospital, School of Medicine, Zhejiang University, Hangzhou, China before joining the study, and the surgical procedures followed our previous study [23] using the LenSx ${ }^{\odot}$ laser system (Alcon, Fort Worth, TX, USA). This system was the first commercially available system for laser cataract surgery, which contains an optical coherence tomography (OCT) system. It uses a disposable curved patient interface for docking and live OCT imaging. The femtosecond laser was used for the capsulotomy, lens fragmentation, and corneal incisions before phacoemulsification. The operated eye was applanated with the disposable interface contact lens of the femtosecond laser system using the suction ring supplied by the manufacturer (SoftFit Patient Interface, AlconLenSx, Inc.). The proprietary energy and spot separation parameters, which had been optimized in previous studies, were used for all procedures. All surgical procedures were performed using standard equipment and by experienced surgeons with an experience of at least 50 FLACS before this study. Postoperative medications were identical for all operated eyes, same as our previous study [23], which consisted of topical dexamethasone tobramycin 4 times a day for 2 weeks and pranoprofen 4 times a day for 1 month.

\section{Outcome assessment}

The primary outcome was the completion rate of a circular anterior capsulotomy. The completion of a circular anterior capsulotomy was defined as complete capsular edge separation being achieved and no manual separation of residual tags is needed. The secondary outcomes were the completion rates of FLACS procedures including lens fragmentation, corneal incision, and successful IOL implantation, as well as the result of BCDVA. If the surgeons observed such situations including but not limited to broken pieces, fragmentation trace of lens nucleus or retrolenticular bubbles after laser lens fragmentation, it would be judged as lens fragmentation completion. The completion of corneal incisions was defined as a blunt spatula can be used to open the laser-incised cornea. The completion of IOL implantation was defined as IOL implantation into the eye successfully during the FLACS. All patients were followed up postoperatively at 1 day ( \pm 1 day), 7 days ( \pm 2 day) and 30 days ( \pm 14 days) regardless of whether the surgery was for the first or second eye. If cataract surgeries were performed in both eyes, the patient was followed up until postoperative day 30 post the surgery of the second eye.

\section{Safety analysis}

All AEs, whether or not related to the investigational product, were collected, recorded, and reported. Serious AEs (SAEs) were defined as AEs that led to: 1) death; 2) any serious deterioration in the condition of the patient; 3) any life-threatening event; 4) any potentially sightthreatening event or permanent impairment to any body structure/function; 5) prolonged hospitalization or new event of hospitalization; 6) any harm due to false positive or false negative result from a diagnostic test that was used within the manufacturer's indications and instructions; and 7) any event leading to threats to normal fetal development and birth.

In addition to reporting all AEs (serious and non-serious) meeting the definitions, the investigators had to report any occurrence of the following as an SAE in this study: capsular tear, vitreous loss, anterior segment hyphema, anterior chamber collapse and iris damage. Treatment emergent AEs (TEAEs) were defined as AEs after study treatment which referred to FLACS in this study.

\section{Statistical analysis}

Assuming a completion rate of a circular anterior capsulotomy of $92 \%$, an $\alpha$ of 0.05 and a power of 0.8 , a sample size of 1500 eyes was estimated to be sufficient to ensure that a precise estimate of the $95 \%$ confidence interval (CI) would fall within a rate of $\pm 1.5 \%$. The data were analyzed using descriptive statistics. Continuous variables were expressed as means \pm standard deviation (SD) or medians (range). Categorical variables were expressed as frequencies and percentages, and compared using the chi-square test or continuity correction $\mathrm{X}^{2}$ test. All statistical analyses were performed using SPSS 21.0 (IBM, Armonk, NY, USA). $P$ value $<0.05$ was considered statistically significant.

\section{Results}

\section{Baseline characteristics}

A total of 1435 patients were enrolled in 19 cataract surgery clinics in China, and 1341 patients (males: 669; 
females: 672) were finally treated (Table 1$)$. Among the patients who dropped out $(n=19), 13$ patients withdrew consent and six were lost to follow-up (Fig. 1). A total of 1542 eyes were included in the final analysis (data for single eye treatment in 1140 patients and for both eyes treatment in 201 patients). The demographic characteristics of patients are presented in Table 2. The mean values of UCDVA, BCDVA, Kmax, and Kmin for all treated eyes were $1.134 \pm 0.831 \operatorname{logMAR}, 0.878 \pm 0.854$ $\operatorname{logMAR}, 44.52 \pm 1.81 \mathrm{D}$, and $43.55 \pm 1.78 \mathrm{D}$, respectively. The average axial length of all treated eyes was $24.53 \pm$ $2.54 \mathrm{~mm}$. Preoperative nuclear density for all treated eyes was $2.8 \pm 0.77$, and the majority of eyes (51.3\%) were classified as having a semi-hard nuclear density. The endothelial cell count at baseline was $2600 \pm 371 / \mathrm{mm}^{2}$ for all treated eyes (Table 3). The spherical power and cylinder power were $4.64 \pm 5.42$ and $1.36 \pm 1.09$ for all treated eyes at baseline.

\section{Primary and secondary outcomes}

According to the results of primary and secondary outcome measures shown in Tables 4 and 5, the completion rate of a circular anterior capsulotomy was $98.6 \%$ (95\% CI: 97.8, 99.1\%) for all 1542 treated eyes. The completion rate of lens fragmentation was 99.5\% (95\% CI: 99.1, 99.8\%) for all treated eyes. Fragmentation was successfully completed for all lenses categorized as soft or semi-soft; the overall lens fragmentation completion rates for lenses with semi-hard, hard and very hard nuclei were 99.5, 99.1 and 94.4\%, respectively. The completion rate of corneal incision was $97.6 \%$ (95\% CI: 96.7, 98.3\%) overall. The completion rate of IOL implantation
Table 2 Demographic characteristics of the patients

\begin{tabular}{ll}
\hline Characteristic & Total $(n=1341)$ \\
\hline Age (years) & $64.8 \pm 13.4$ \\
Sex, $n(\%)$ & \\
$\quad$ Male & $669(49.9)$ \\
$\quad$ Female & $672(50.1)$ \\
Ethnicity, $n(\%)$ & \\
$\quad$ Han & $1327(99.0)$ \\
Others & $14(1.0)$ \\
\hline
\end{tabular}

Data are shown as mean \pm standard deviation, unless otherwise stated

was $100 \%$ (95\% CI: 99.8, 100\%) for all treated eyes. Baseline BCDVA was $0.887 \pm 0.861 \log$ MAR. Improvement occurred postoperatively with BCDVA $0.186 \pm 0.324$ logMAR at postoperative day 7 and $0.158 \pm 0.291 \log$ MAR at postoperative day 30 at the follow-up points. The proportion of all treated eyes with a BCDVA of 20/20 or better was $1.6 \%$ at baseline, $36.5 \%$ at postoperative day 7 and $41.3 \%$ at postoperative day 30 . The proportion of all treated eyes with a BCDVA worse than $20 / 40$ was $74.1 \%$ at baseline, $15.2 \%$ at postoperative day 7 , and $12.6 \%$ at postoperative day 30 .

\section{Safety}

One pre-treatment $\mathrm{AE}$ of hypertension was reported. TEAEs occurred in five treated eyes (an incidence of $0.32 \%$ ), whereas no treatment-emergent non-ocular AEs was reported. The most frequent TEAE was miosis (nine cases, $0.58 \%$ ), which was defined as an obvious pupil diameter decrease that influence the following surgical procedure. All these cases were of mild severity and

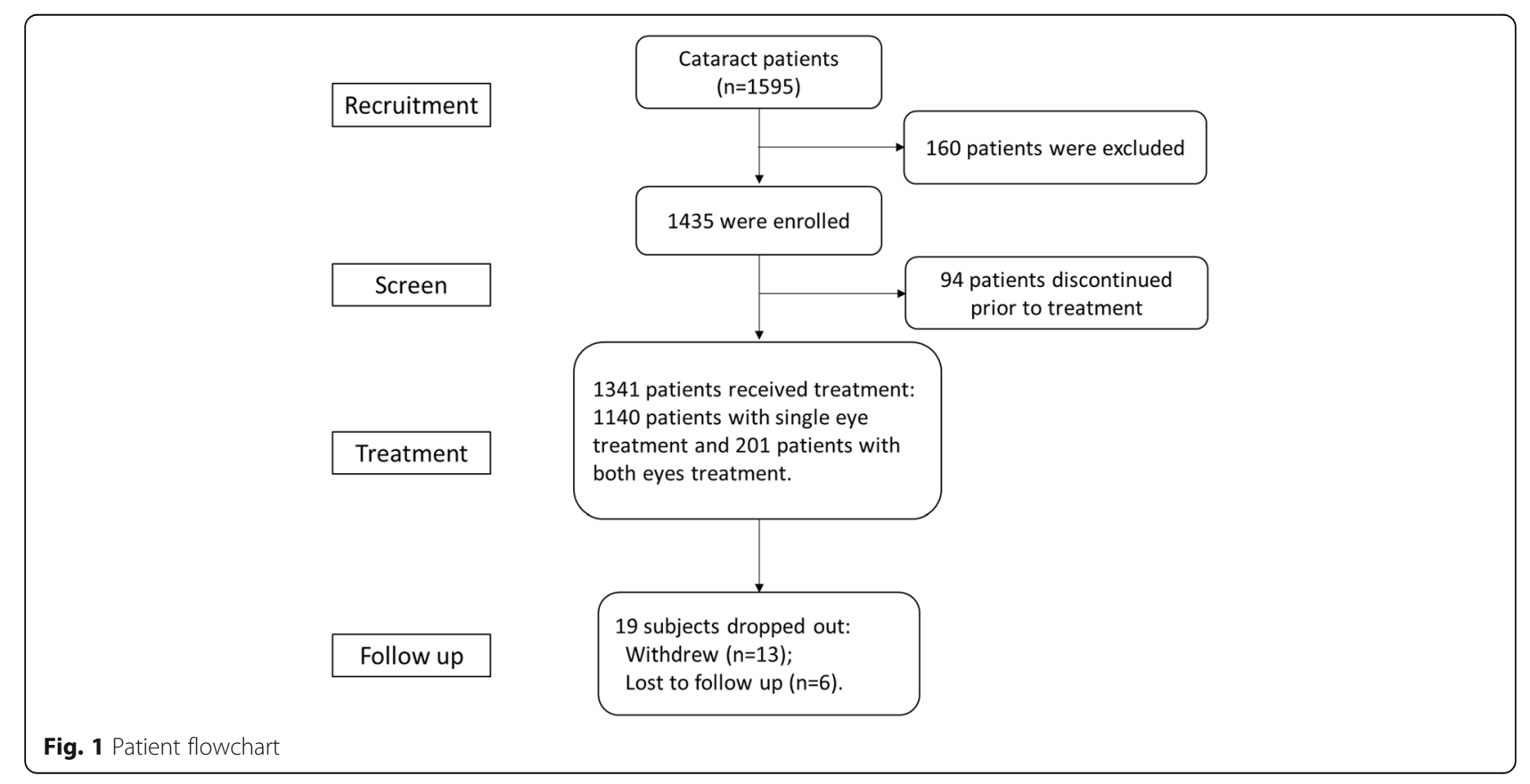


Table 3 Baseline characteristics of eyes

\begin{tabular}{ll}
\hline Characteristic & Total $(n=1542)$ \\
\hline UCDVA (logMAR) & $1.134 \pm 0.831$ \\
BCDVA (logMAR) & $0.878 \pm 0.854$ \\
Kmax (Diopters) & $44.52 \pm 1.81$ \\
Kmin (Diopter) & $43.55 \pm 1.78$ \\
Axial length (mm) & $24.53 \pm 2.54$ \\
Nuclear density, $n(\%)$ & \\
Soft & $51(3.3)$ \\
Semi-soft & $448(29.0)$ \\
Semi-hard & $791(51.3)$ \\
Hard & $233(15.1)$ \\
Very hard & $18(1.2)$ \\
Missing data & $1(0.1)$ \\
Endothelial cell count $\left(/ \mathrm{mm}^{2}\right)$ & $2600 \pm 371$
\end{tabular}

Data are shown as mean \pm standard deviation, unless otherwise stated. BCDVA best corrected distance visual acuity, Kmax maximum keratometry reading, Kmin minimum keratometry reading, UCDVA uncorrected distance visual acuity

considered related to the investigational product. The second most frequent TEAE was posterior capsule rupture (three cases, 0.19\%), which was considered as a SAE. All three cases of posterior capsule rupture were of moderate severity; two were considered not related to the investigational product or procedure while one was deemed related to the investigational product. Lens fragmentation was completed for all three patients with posterior capsule rupture. Phaco surgery and IOL implantation were all completed in these three patients and no patients discontinued from the study because of AEs. Other TEAEs included vertigo (one case, $0.064 \%$ ), which was of mild severity and considered not related to the investigational product or procedure.

Table 4 Primary and secondary outcomes

\begin{tabular}{ll}
\hline Variable & Total $(n=1542)$ \\
\hline $\begin{array}{l}\text { Completion of a circular anterior capsulotomy } \\
95 \% \mathrm{Cl}\end{array}$ & $1520(98.6)$ \\
Completion of lens fragmentation & $97.8,99.1$ \\
$n(\%)$ & \\
$95 \% \mathrm{Cl}$ & $1535(99.5)$ \\
Completion of corneal incision & $99.1,99.8$ \\
$n(\%)$ & \\
$95 \% \mathrm{Cl}$ & $1505(97.6)$ \\
Completion of IOL implantation & $96.7,98.3$ \\
$n(\%)$ & \\
$95 \% \mathrm{Cl}$ & $1542(100)$ \\
\hline
\end{tabular}

$\mathrm{Cl}$ confidence interval, $\mathrm{OL}$ intra-ocular lens
Table 5 Best corrected distance visual acuity (BCDVA)

\begin{tabular}{ll}
\hline BCDVA (Snellen Chart) & Total $(n=1542)$ \\
\hline Baseline & 1527 \\
$n$ & $24(1.6)$ \\
$20 / 20$ or better & $77(5.0)$ \\
$20 / 25$ & $31(2.0)$ \\
$20 / 32$ & $264(17.3)$ \\
$20 / 40$ & $1131(74.1)$ \\
Worse than 20/40 & \\
Day 7 & 1527 \\
$n$ & $557(36.5)$ \\
$20 / 20$ or better & $364(23.8)$ \\
$20 / 25$ & $50(3.3)$ \\
$20 / 32$ & $324(21.2)$ \\
$20 / 40$ & $232(15.2)$ \\
Worse than 20/40 & \\
Day 30 & 1520 \\
$n$ & $628(41.3)$ \\
$20 / 20$ or better & $379(24.9)$ \\
$20 / 25$ & $37(2.4)$ \\
$20 / 32$ & $285(18.8)$ \\
$20 / 40$ & $191(12.6)$ \\
Worse than 20/40 &
\end{tabular}

Data are presented as $n(\%)$

\section{Discussion}

FLACS is becoming increasingly used in the management of cataract, and several recent meta-analyses have identified advantages of FLACS over manual phacoemulsification including improved capsulotomy quality, reduced effective phaco time and energy, smaller changes in central corneal thickness, less corneal endothelial cell loss, and better visual outcomes in the short-term [24, 25]. The present study was designed to investigate the performance of the LenSx $\mathrm{x}^{\oplus}$ laser system in real-world medical practice in Chinese patients with cataract. The main findings were that completion of a circular capsulotomy, lens fragmentation, IOL implantation, and corneal incision were successfully achieved in the vast majority of patients. Furthermore, the majority of treated eyes (66.2\%) had a BCDVA of $20 / 25$ or better at postoperative day 30 , compared with only $6.6 \%$ at baseline; only $12.6 \%$ of treated eyes had a BCDVA worse than 20/40. In addition, AEs were reported in only $0.32 \%$ of cases, and the incidence of posterior capsule rupture was only $0.19 \%$. These real-world clinical data in a large sample of patients support the conclusions of previous studies that FLACS is an effective and safe technique for the treatment of cataract.

The use of the LenSx ${ }^{\oplus}$ laser system in the present study achieved a $98.6 \%$ completion rate for circular 
capsulotomy. This is similar to the results of a previous study of the LenSx ${ }^{\circ}$ laser system in Japanese eyes (98.7\%) [26]. In this study, complications were seen in only $0.32 \%$ of patients, and posterior capsule rupture occurred in only $0.19 \%$ of patients. This could be due to more circular and precisely sized capsulotomies using FLACS than when using manual capsulorhexis $[12,27]$. In addition, the completion of a circular anterior capsulotomies was defined as achieving complete capsular edge separation without manual separation of residual tags during surgery. This broad definition may have improved our completion rate. The completion rate for lens fragmentation (99.5\%) was high and the lens fragmentation completion rates for lenses with semi-hard, hard, and very hard nuclei were 99.5, 99.1, and 94.4\%. The completion rate of corneal incision (97.6\%) was also very high. The high completion rate may be attributed to the rich experience of the investigators and strict inclusion criteria. In this study enrollment did not include patients with any contraindications to FLACS such as white cortical cataracts with a hard nucleus, corneal disease and dense corneal scar, in which a femtosecond laser could not be used for lens fragmentation or corneal incision. The completion rate of IOL implantation was $100 \%$ in our study. Previous study also suggested that FLACS can obtain better IOL centration than manual capsulotomy $[12,13]$, indicating a possible advantage of FLACS over conventional methods.

Visual outcomes are the primary concern for patients having cataract surgery. In this study, most patients achieved improved UCDVA and BCDVA postoperatively. The average value of BCDVA was $0.887 \log$ MAR at baseline and $0.158 \operatorname{logMAR}$ at postoperative day 30, indicating a substantial improvement. Furthermore, before surgery, $74.1 \%$ of patients had a BCDVA worse than $20 / 40$, and only $1.6 \%$ had a BCDVA of $20 / 20$ or better. By contrast, the corresponding values 30 days after FLACS were 12.6 and $41.3 \%$, respectively. Our data are broadly in agreement with other published studies reporting improvements in BCDVA to between 0.004 and $0.89 \log$ MAR at 1-3 months after FLACS [28] or in UCDVA to 0.12logMAR [29]. Other studies have reported that after FLACS, $97.5 \%$ of patients achieved a BCDVA of 20/40 or better [30] which were consistent with the present results. It is also notable in our study that the BCDVA data at postoperative day 7 (BCDVA of $0.186 \pm 0.324 \log$ MAR with $36.5 \%$ of patients obtained a BCDVA of $20 / 20$ or better and $15.2 \%$ worse than $20 / 40$ ) were broadly similar to those at postoperative day 30 , suggesting that recovery of visual acuity after FLACS was rapid.

In this study, the most frequent intraoperative complication of FLACS was miosis $(0.58 \%)$. In a previous study, Manning et al. reported eight cases of miosis in 2814
(0.3\%) femtosecond-assisted cases, and 60 (1.2\%) miosis in 4987 conventional phacoemulsification cases. They also demonstrated that the lower rate of miosis in the FLACS group may be related to that FLACS keeps a $1000-\mu \mathrm{m}$ distance between the iris and capsule to prevent iris damage and subsequent intraoperative miosis [28]. In this study, there were three cases of reported posterior capsule rupture as SAE, which occurred in the process of phacoemulsification. Among the three cases, two patients underwent anterior vitrectomy. All patients with posterior capsule rupture were implanted IOL successfully and the postoperative vision recovered well. In 2015, Chen reported two cases of inadvertent opening in the posterior capsule when the LenSx Laser was used on 273 eyes. They did not find the exact cause but the author emphasized the importance of proper training to ensure the safety and the effect of FLACS [18].

This study has several limitations. First, this was a single-arm registry study, hence comparisons of outcomes and complications between FLACS and manual phacoemulsification were not undertaken. The inclusion criteria did not specify the baseline BCDVA and comorbidity, which might result in a low proportion of patients achieving 20/20. Second, although this was a multi-center study, the majority of patients were of Han origin, so the generalizability of these findings to other ethnicities remains unknown. Third, detailed analyses of data for additional visual outcomes such as UCDVA and mean absolute error of refraction were not performed. Fourth, measurement of phaco time and energy, endothelial cell density, central corneal thickness, central retinal thickness and IOL centration were not included as assessed parameters. Further studies are needed to confirm and extend our findings.

\section{Conclusions}

The present registry study indicated that FLACS using the LenS $\mathrm{x}^{\oplus}$ laser system can achieve satisfactory results in a real-world setting. Our analysis of real-world clinical data from Chinese patients with cataract suggests that FLACS using the LenSx $x^{\circ}$ laser system is an effective and safe technique for the surgical management of cataract.

\section{Additional file}

Additional file 1: Participating centers. This file includes the name of participating centers, region, the number of enrolled patients at each center, and the approval numbers. (DOCX $18 \mathrm{~kb}$ )

\section{Abbreviations}

AE: adverse event; BCDVA: best corrected distance visual acuity; CCC: continuous curvilinear capsulorhexis; Cl: confidence interval CSR: cataract surgery rates; FLACS: femtosecond laser-assisted cataract surgery; IOL: intraocular lens; LogMAR: logarithm of the minimal angle of resolution; OCT: optical coherence tomography; SAE: serious adverse event; 
SD: standard deviation; TEAE: treatment emergent adverse event; UCDVA: uncorrected distance visual acuity

\section{Acknowledgements}

The authors would like to thank all the employees who agreed to participate in this study and all the patients involved in this study for their cooperation and support.

\section{Funding}

This study received no specific grant from any funding agency in the public, commercial or not-for-profit sectors.

\section{Availability of data and materials}

The datasets used and analyzed during the current study are not publicly available as they are related to the patients' privacy, but they are available from the corresponding author on reasonable request.

\section{Authors' contributions}

XBZ conceived and coordinated the study, designed, performed and analyzed the experiments, wrote the paper. KY conceived and coordinated the study, designed, performed, revised the paper and provided critical technical and material support. YHY, GBZ, YWZ, GYZ, MSC, YW, SQZ and HZ carried out the data collection, data analysis, and revised the paper. All authors reviewed the results and approved the final version of the manuscript.

\section{Ethics approval and consent to participate}

This study was approved by the ethics committees of all the participating centers (Additional file 1) and adhered to the principles of the Declaration of Helsinki. Written informed consent was obtained from all individual participants included in the study.

\section{Consent for publication}

Not applicable.

\section{Competing interests}

The authors declare that they have no competing interest.

\section{Publisher's Note}

Springer Nature remains neutral with regard to jurisdictional claims in published maps and institutional affiliations.

\section{Author details \\ ${ }^{1}$ Eye Center, Second Affiliated Hospital, School of Medicine, Zhejiang University, Hangzhou, China. ${ }^{2}$ Cataract, Xiamen Eye Center, Xiamen, China. ${ }^{3}$ Cataract, Shenyang Aier Eye Hospital, Shenyang, China. ${ }^{4}$ Cataract, Fuzhou Southeast Ophthalmology Hospital, Fuzhou, China. ${ }^{5}$ Cataract, Chongqing Aier Ophthalmology Hospital, Chongqing, China. ${ }^{6}$ Cataract, Wuhan Aier Eye Hospital, Wuhan, China. ${ }^{7}$ Ophthalmology, Beijing Tongren Hospital, Beijing, China. ${ }^{8}$ Cataract, Ophthalmology Hospital of Tianjin Medical College, Tianjin, China.}

\section{Received: 30 September 2018 Accepted: 1 March 2019}

Published online: 14 March 2019

\section{References}

1. Lam D, Rao SK, Ratra V, Liu Y, Mitchell P, King J, Tassignon MJ, Jonas J, Pang CP, Chang DF. Cataract. Nat Rev Dis Prim. 2015;1:15014.

2. Rao GN, Khanna R, Payal A. The global burden of cataract. Curr Opin Ophthalmol. 2011;22(1):4-9.

3. Khairallah M, Kahloun R, Bourne R, Limburg H, Flaxman SR, Jonas JB, Keeffe J, Leasher J, Naidoo K, Pesudovs K, et al. Number of people blind or visually impaired by cataract worldwide and in world regions, 1990 to 2010. Invest Ophthalmol Vis Sci. 2015;56(11):6762-9.

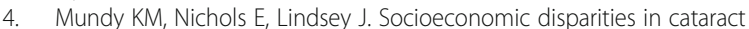
prevalence, characteristics, and management. Semin Ophthalmol. 2016; 31(4):358-63.

5. Tang Y, Wang X, Wang J, Huang W, Gao Y, Luo Y, Yang J, Lu Y. Prevalence of age-related cataract and cataract surgery in a Chinese adult population: the Taizhou eye study. Invest Ophthalmol Vis Sci. 2016;57(3):1193-200.
6. Wang W, Yan W, Fotis K, Prasad NM, Lansingh VC, Taylor HR, Finger RP, Facciolo D, He M. Cataract surgical rate and socioeconomics: a global study. Invest Ophthalmol Vis Sci. 2016;57(14):5872-81.

7. Dick HB, Schultz T. A review of laser-assisted versus traditional phacoemulsification cataract surgery. Ophthalmol Therapy. 2017;6(1):7-18.

8. Agarwal A, Jacob S. Current and effective advantages of femto phacoemulsification. Curr Opin Ophthalmol. 2017;28(1):49-57.

9. Chan T, Pattamatta U, Butlin M, Meades K, Bala C. Intereye comparison of femtosecond laser-assisted cataract surgery capsulotomy and manual capsulorhexis edge strength. J Cataract Refract Surg. 2017;43(4):480-5.

10. Auffarth GU, Reddy KP, Ritter R, Holzer MP, Rabsilber TM. Comparison of the maximum applicable stretch force after femtosecond laser-assisted and manual anterior capsulotomy. J Cataract Refract Surg. 2013;39(1):105-9.

11. Pajic B, Cvejic Z, Pajic-Eggspuehler B. Cataract surgery performed by high frequency LDV Z8 femtosecond laser: safety, efficacy, and its physical properties. Sensors (Basel, Switzerland). 2017;17(6).

12. Mastropasqua L, Toto L, Mattei PA, Vecchiarino L, Mastropasqua A, Navarra R, Di Nicola M, Nubile M. Optical coherence tomography and 3-dimensional confocal structured imaging system-guided femtosecond laser capsulotomy versus manual continuous curvilinear capsulorhexis. J Cataract Refract Surg. 2014;40(12):2035-43.

13. Toto L, Mastropasqua R, Mattei PA, Agnifili L, Mastropasqua A, Falconio G, Di Nicola M, Mastropasqua L. Postoperative IOL axial movements and refractive changes after femtosecond laser-assisted cataract surgery versus conventional phacoemulsification. J Refract Surg (Thorofare, NJ: 1995). 2015: 31(8):524-30.

14. Kanellopoulos AJ, Asimellis G. Standard manual capsulorhexis / ultrasound phacoemulsification compared to femtosecond laser-assisted capsulorhexis and lens fragmentation in clear cornea small incision cataract surgery. Eye Vision (London, England). 2016:3:20.

15. Chen $X, Y u$ Y, Song $X$, Zhu Y, Wang W, Yao K. Clinical outcomes of femtosecond laser-assisted cataract surgery versus conventional phacoemulsification surgery for hard nuclear cataracts. J Cataract Refract Surg. 2017:43(4):486-91.

16. Titiyal JS, Kaur M, Singh A, Arora T, Sharma N. Comparative evaluation of femtosecond laser-assisted cataract surgery and conventional phacoemulsification in white cataract. Clin Ophthalmol (Auckland, NZ). 2016;10:1357-64.

17. Diakonis VF, Yesilirmak N, Cabot F, Kankariya VP, Kounis GA, Warren D, Sayed-Ahmed IO, Yoo SH, Donaldson K. Comparison of surgically induced astigmatism between femtosecond laser and manual clear corneal incisions for cataract surgery. J Cataract Refract Surg. 2015;41(10):2075-80.

18. Chen M, Swinney C, Chen M. Comparing the intraoperative complication rate of femtosecond laser-assisted cataract surgery to traditional phacoemulsification. Int J Ophthalmol. 2015:8(1):201-3.

19. Conrad-Hengerer I, Al Juburi M, Schultz T, Hengerer FH, Dick HB. Corneal endothelial cell loss and corneal thickness in conventional compared with femtosecond laser-assisted cataract surgery: three-month follow-up. J Cataract Refract Surg. 2013;39(9):1307-13.

20. Takacs Al, Kovacs I, Mihaltz K, Filkorn T, Knorz MC, Nagy ZZ. Central corneal volume and endothelial cell count following femtosecond laser-assisted refractive cataract surgery compared to conventional phacoemulsification. J Refract Surg (Thorofare, NJ: 1995). 2012;28(6):387-91.

21. Nagy ZZ, Ecsedy M, Kovacs I, Takacs A, Tatrai E, Somfai GM, Cabrera DeBuc D. Macular morphology assessed by optical coherence tomography image segmentation after femtosecond laser-assisted and standard cataract surgery. J Cataract Refract Surg. 2012;38(6):941-6.

22. Emery JM, Little JH. Phacoemulsification and aspiration of cataracts: surgical techniques, complications, and results: Mosby; 1979.

23. Yu Y, Chen X, Hua H, Wu M, Lai K, Yao K. Comparative outcomes of femtosecond laser-assisted cataract surgery and manual phacoemusification: a six-month follow-up. Clin Exp Ophthalmol. 2016:44(6):472-80.

24. Day AC, Gore DM, Bunce C, Evans JR. Laser-assisted cataract surgery versus standard ultrasound phacoemulsification cataract surgery. Cochrane Database Syst Rev. 2016;7:Cd010735.

25. Chen $\mathrm{X}$, Chen $\mathrm{K}$, He J, Yao K. Comparing the curative effects between femtosecond laser-assisted cataract surgery and conventional phacoemulsification surgery: a meta-analysis. PLoS One. 2016;11(3):e0152088.

26. Bissen-Miyajima H, Hirasawa M, Nakamura K, et al. Safety and reliability of femtosecond laser-assisted cataract surgery for Japanese eyes. Jpn J Ophthalmol. 2018;62(2):226-30. 
27. Reddy KP, Kandulla J, Auffarth GU. Effectiveness and safety of femtosecond laser-assisted lens fragmentation and anterior capsulotomy versus the manual technique in cataract surgery. J Cataract Refract Surg. 2013;39(9):1297-306.

28. Manning S, Barry P, Henry Y, Rosen P, Stenevi U, Young D, Lundstrom M.

Femtosecond laser-assisted cataract surgery versus standard phacoemulsification cataract surgery: study from the European registry of quality outcomes for cataract and refractive surgery. J Cataract Refract Surg. 2016:42(12):1779-90.

29. Wang Y, Bao X, Zhou Y, Xu R, Peng T, Sun M, Cao D, He L. Preliminary evaluation of the femtosecond laser-assisted cataract surgery in 300 cases. Zhonghua Yan KeZa Zhi. 2015:51(9):689-93.

30. Oakley CL, Ewe SY, Allen PL, Vote BJ. Visual outcomes with femtosecond laser-assisted cataract surgery versus conventional cataract surgery in toric IOL insertion. Clin Exp Ophthalmol. 2016;44(7):570-3.

Ready to submit your research? Choose BMC and benefit from:

- fast, convenient online submission

- thorough peer review by experienced researchers in your field

- rapid publication on acceptance

- support for research data, including large and complex data types

- gold Open Access which fosters wider collaboration and increased citations

- maximum visibility for your research: over $100 \mathrm{M}$ website views per year

At BMC, research is always in progress.

Learn more biomedcentral.com/submissions 